\title{
Drying and rewetting conditions differentially affect the mineralization of fresh plant litter and extant soil organic matter
}

\author{
Luis Lopez-Sangil ${ }^{1,2^{*}}$, Iain P. Hartley ${ }^{3}$, Pere Rovira ${ }^{4}$, Pere Casals ${ }^{4}$, Emma J. Sayer ${ }^{5}$ \\ ${ }^{1}$ Department of Evolutionary Biology, Ecology and Environmental Sciences. Universitat de Barcelona, Av. Diagonal 643, \\ Barcelona, 08028, Spain. \\ ${ }^{2}$ Crops, Environment \& Land use Research Centre, Teagasc, Johnstown Castle, Co. Wexford, Ireland. \\ ${ }^{3}$ Geography, College of Life and Environmental Sciences, University of Exeter, Amory building, Rennes Drive, Exeter, EX4 \\ 4RJ, UK. \\ ${ }^{4}$ Forest Sciences Centre of Catalonia (CTFC), Ctra. Sant Llorenç de Morunys, km 2, Solsona, 25280, Spain. \\ ${ }^{5}$ Lancaster Environment Centre, Lancaster University, Lancaster, LA1 4YQ, UK.
}

\begin{abstract}
Drought is becoming more common globally and has the potential to alter patterns of soil carbon (C) storage in terrestrial ecosystems. After an extended dry period, a pulse of soil $\mathrm{CO}_{2}$ release is commonly observed upon rewetting (the so-called 'Birch effect'), the magnitude of which depends on soil rewetting frequency. But the source and implications of this $\mathrm{CO}_{2}$ efflux are unclear. We used a mesocosm field experiment to subject agricultural topsoil to two distinct drying and rewetting frequencies, measuring Birch effects (as 3-day cumulative $\mathrm{CO}_{2}$ efflux upon rewetting) and the overall $\mathrm{CO}_{2}$ efflux over the entire drying-rewetting cycle. We used ${ }^{14} \mathrm{C}$-labelled wheat straw to determine the contribution of fresh (recently incorporated) plant litter or extant soil organic matter (SOM) to these fluxes, and assessed the extent to which the amount of soil microbial biomass $+\mathrm{K}_{2} \mathrm{SO}_{4}$-extractable organic $\mathrm{C}$ (fumigated-extracted $\mathrm{C}$, FEC) before rewetting determined the magnitude of Birch effect $\mathrm{CO}_{2}$ pulses. Our results showed a gradual increase in SOM-derived organic solutes within the FEC fraction, and a decrease in soil microbial biomass, under more extreme drying and rewetting conditions. But, contrary to our hypothesis, pre-wetting levels of FEC were not related to the magnitude of the Birch effects. In the longer term, rewetting frequency and temperature influenced the overall (31-day cumulative) amount of $\mathrm{CO}_{2}-\mathrm{C}$ released from SOM upon rewetting, but the overall ${ }^{14} \mathrm{CO}_{2}-\mathrm{C}$ respired from fresh straw was only influenced by the rewetting frequency, with no effect of seasonal temperature differences of $\sim 15^{\circ} \mathrm{C}$. We conclude that the mineralization of fresh plant litter in soils is more sensitive to water limitations than extant SOM in soils under drying-rewetting conditions. Moreover, we found little evidence to support the hypothesis that the availability of microbial and soluble organic $\mathrm{C}$ before rewetting determined the magnitude of the Birch effects, and suggest that future work should investigate whether these short-term $\mathrm{CO}_{2}$ pulses are predominantly derived from substrate-supply mechanisms resulting from the disruption of the soil organo-mineral matrix.
\end{abstract}

\footnotetext{
${ }^{*}$ Corresponding author: Luis Lopez-Sangil; bioluisinho@gmail.com. Current address: Crops, Environment \& Land use Research Centre, Teagasc, Johnstown Castle, Co. Wexford, Ireland.
} 


\section{Introduction}

When a dried soil is rewetted, an immediate sharp increase in $\mathrm{CO}_{2}$ efflux typically follows. This peak of $\mathrm{CO}_{2}$ efflux upon rewetting is referred to as the 'Birch effect' (Birch, 1958; Jarvis et al., 2007), which has a mean, albeit variable, duration of 3-4 days (Kim et al., 2012). It has been observed in a wide range of terrestrial ecosystems and under laboratory conditions, and may represent a substantial proportion of the total annual $\mathrm{CO}_{2}$ efflux in arid, semi-arid and Mediterranean soils (Borken and Matzner, 2009; Kim et al., 2012). Previous work has shown that the Birch effect can be attributed to a large increase in the microbial mineralization (respiration) of soil organic matter and the release of $\mathrm{CO}_{2}-\mathrm{C}$ into the atmosphere (Casals et al., 2011), but the specific sources of organic $\mathrm{C}$ that contribute to this $\mathrm{CO}_{2}$ flux are less clear.

A number of experiments have shown that many factors can modulate the magnitude of soil $\mathrm{C}$ release by the Birch effect. Respiration peaks only occur when there are substantial differences between pre- and post-rewetting soil water content (Chowdhury et al., 2011), and the amount of soil organic matter (SOM) mineralized upon rewetting normally declines with increasing number of previous drying-rewetting (D-RW) cycles (Mikha et al., 2005; Wu and Brookes, 2005), which suggests that the mineralization of SOM after rewetting is related to the number and extent of previous soil desiccations (Williams and Xia, 2009; Unger et al., 2010; Chowdhury et al., 2011). The availability of SOM to soil microorganisms before rewetting is also thought to regulate the magnitude of the rewetting response (Casals et al., 2009), and soil temperature and/or water content after rewetting may also play a role (Cable et al., 2011; Suseela et al., 2012). The relative importance of these multiple factors and their interactions are still a source of great uncertainty for predicting the magnitude of soil respiration responses to the expected extension of dry periods in many ecosystems (Wetherald and Manabe, 2002; Borken and Matzner, 2009; Falloon et al., 2011; Suseela et al., 2012).

Several mechanisms are thought to contribute to the post-rewetting increase in SOM mineralization, and many of them are closely related to the supply of organic substrates in the soil solution: i) release of intracellular compounds from microbial cell lysis after severe soil desiccation, and subsequent respiration by surviving microbes (Bottner, 1985); ii) microbial release, re-uptake and respiration of intracellular osmolytes, to cope with the sudden increase of soil water potential upon rewetting (Kieft et al., 1987; Halverson et al., 2000; Fierer and Schimel, 2003); iii) spatial redistribution of soil microorganisms and/or organic solutes upon rewetting, due to increased mobility of microbes or substrate within soil pores (Van Gestel et al., 1993; Xiang et al., 2008); iv) desorption of soluble SOM from a plethora of organo-mineral complexes (Kalbitz et al., 2000; Lopez-Sangil and Rovira, 2013); and v) aggregate disruption and exposure of previously occluded SOM particles during the drying phase or upon rewetting (Denef et al., 2001). The relative contribution of these mechanisms is poorly understood and likely to be modulated by factors such as soil structure or depth within the profile, which determine levels of water retention and rewetting abruptness under D-RW conditions (Xiang et al., 2008; Sanaullah et al., 2011; Rovira and Vallejo, 1997). For instance, desiccation and rewetting extremes decline with soil depth (Sanaullah et al., 2011; Lopez-Sangil et al., 2013), 
which may promote specific mechanisms over others as they exhibit different sensitivities to physical disturbance (Borken and Matzner, 2009; Williams and Xia, 2009).

The relationship between SOM decomposition rates and the size of the soil microbial biomass is the subject of much debate, but it is also directly relevant to C dynamics during D-RW cycles (Coleman and Jenkinson, 1996; Shen et al., 1997; Probert et al., 1998; Sato and Seto, 1999; Franzluebbers et al., 2000; Bapiri et al., 2010). A major portion of the soil microbial biomass can be in a dormant or in a completely non-viable state in dry soil, and consequently the supply of available substrates (rather than the size of microbial biomass) could be a better predictor of the magnitude of SOM mineralization upon rewetting (Wang et al., 2003). The amount of soluble (i.e., extractable) organic $\mathrm{C}$ has been proposed as an indicator of substrate availability for soil microbes (Boyer and Groffman, 1996), and this C fraction may help to explain the dynamics of SOM mineralization during D-RW cycles (Wang et al., 2003; Casals et al., 2009). Improving our understanding of these relationships could refine our modeling tools and landuse strategies for reducing soil $\mathrm{C}$ release to the atmosphere.

A potential way to address some of these uncertainties is to assess separately the contributions of fresh organic matter (recently incorporated) and extant SOM (more stable) as potential C sources of the Birch effect. Distinguishing between these two substrates can enhance our mechanistic understanding of soil C respiration sources (Bottner, 1985; Casals et al., 2000), and can provide modelers with information about how the mineralization of different organic substrates in soil may respond distinctly to changes in pedoclimatic conditions. Although fresh plant litter decomposition exhibits a lower sensitivity to temperature than SOM due to its lower recalcitrance (Bosatta and Agren, 1999), previous work shows that, contrastingly, it can be very susceptible to water limitations (Rovira and Vallejo, 1997; Magid et al., 1999). This susceptibility is not necessarily related to substrate quality (Sanaullah et al., 2012), but could be a result of decreased substrate availability during desiccation, or greater drought sensitivity of litter-decomposing microbes, although the mechanisms involved are still speculative. Moreover, it is still uncertain how soil temperature and moisture interact to control the mineralization of distinct substrates during Birch effects.

In this study, we hypothesized that 1 ) the amount of $\mathrm{C}$ that is available to microbes (i.e., readily accessible) before rewetting will explain the magnitude of $\mathrm{CO}_{2}$ release during subsequent Birch effects; and 2) the mineralization of extant soil organic matter would be less affected by extended drought periods than that of fresh plant litter inputs. To test these hypotheses, we assessed the effect of extended drought periods on microbial biomass and soluble (i.e., extractable) organic $\mathrm{C}$ fractions in a Mediterranean agricultural soil, and its subsequent impact on soil $\mathrm{CO}_{2}$ emissions. By incubating soil horizons mixed with ${ }^{14} \mathrm{C}$-labelled wheat straw at different depths, we aimed to identify which soil $\mathrm{C}$ sources are mostly affected by D-RW conditions and more able to explain the observed Birch effect $\mathrm{CO}_{2}$ pulses.

\section{Material and methods}

\subsection{Experimental design and straw ${ }^{14} \mathrm{C}$-labelling}


We assessed the influence of two distinct drying-rewetting frequencies on two different simulated soil profiles, using the mesocosm incubation design described in Lopez-Sangil et al. (2013). We constructed 44 mesocosms, each consisting of a PVC cylinder (12-cm inner diameter, 24-cm height) with a funnel, a 2.7- $\mu \mathrm{m}$ glass microfiber filter and a nylon tube attached to the bottom to collect possible leachates (Figure 1). Each mesocosm was packed with $560 \mathrm{~g}$ agricultural topsoil (henceforth, 'topsoil') and $2635 \mathrm{~g}$ mineral subsoil (see section 2.2), simulating a $20-\mathrm{cm}$ depth soil profile. Both soils were air-dried, homogenised and sieved (2$\mathrm{mm}$ ) before filling the mesocosms. To trace the carbon from recent plant litter inputs, the topsoil in each mesocosm was thoroughly mixed with homogeneously ${ }^{14} \mathrm{C}$-labelled wheat straw $(0.42$ g straw $\mathrm{kg}^{-1}$ soil; fragment size $2 \mathrm{~mm}-50 \mu \mathrm{m} ; 2550.9 \mathrm{~Bq} \mathrm{mg}^{-1} \mathrm{C}$ ). The initial total organic $\mathrm{C}$ content of the labelled topsoil was $25.35 \mathrm{mg} \mathrm{C} \mathrm{g} \mathrm{soil}{ }^{-1}$, of which $0.62 \%$ was labelled straw (equivalent to $2 \mathrm{~kg}$ straw ha ${ }^{-1}$ ). The topsoil formed a 4-cm deep horizon (bulk density $=1.24 \mathrm{~g}$ $\left.\mathrm{cm}^{-3}\right)$ and a 7-mm pore nylon mesh separated the topsoil from the mineral subsoil $\left(1.61 \mathrm{~g} \mathrm{~cm}^{-}\right.$ 3) while maintaining hydraulic conductance. As the intensity of drying-rewetting cycles declines with soil depth (Sanaullah et al., 2011; Lopez-Sangil et al., 2013), we accounted for differences in drying-rewetting disturbance with depth by distinguishing two 'depth treatments': the topsoil horizon was placed on the surface of 22 mesocosms $(0-4 \mathrm{~cm}$; 'surface mesocosms'), whereas in the other 22 mesocosms, the topsoil formed a subsurface horizon at 10-14 cm depth ('subsurface mesocosms'; Figure 1).

\subsection{Soil substrates}

The agricultural topsoil was a clay loam Haplic Calcisol (IUSS Working Group WRB, 2006) with an organic $\mathrm{C}$ content of $2.52 \%$ and carbonate content of $37.9 \%$. It was collected from the upper $10-15 \mathrm{~cm}$ of a maize cropland (Zea mays L.) in north-eastern Spain $\left(42^{\circ} 16^{\prime} 51 \mathrm{\prime} \mathrm{N}\right.$; $2^{\circ} 58$ '37"E). The mineral subsoil was a sandy loam with very low organic $\mathrm{C}$ and carbonate concentrations $(0.12 \%$ and $0.8 \%$ respectively), obtained from a nearby quarry. Further details are given in Lopez-Sangil et al. (2013).

\subsection{Incubation and irrigation frequencies}

The mesocosms were subjected to two different drying-rewetting frequencies and incubated for 366 days under field conditions. To maintain natural daily and seasonal variation of soil temperature, we incubated the mesocosms at the experimental field site of the University of Barcelona, sunken in the ground so that the surface of the mesocosm soil profile was levelled with the surrounding soil. A plastic cover protected the area from rainfall, increasing air temperature by $2-3{ }^{\circ} \mathrm{C}$. Mean annual temperature of topsoil horizons was $21{ }^{\circ} \mathrm{C}$ for all treatments. To avoid external $\mathrm{C}$ inputs, we kept the mesocosms plant-free by carefully removing any germinating seedlings.

Each irrigation event consisted of applying $350 \mathrm{ml}$ solution per mesocosm $(0.35 \mathrm{mM} \mathrm{CaCl})$ during 20-25 min, simulating heavy rainfall $\left(31 \mathrm{~L} \mathrm{~m}^{-2}\right)$. Each event accounted for $53 \%$ of the water holding capacity (WHC) of the entire mesocosm profile, avoiding water limitations for soil microbial activity (e.g., Wu and Brookes, 2005; Miller et al., 2005; Gordon et al., 2008). 
We used $\mathrm{CaCl}_{2}$ solution rather than deionised water to maintain conductivity and soil structure (Kjaergaard et al., 2004).

All mesocosms were first irrigated on 22 November 2006, and left to dry for two months ('installation period') to allow the soil columns to settle and also minimize the potential impact of priming effects from the added straw during the irrigation period (Guenet et al., 2010). During the installation period, only soil respiration measurements were performed (see below). On 15 January 2007, we started the 366-day 'irrigation period' using two distinct soil rewetting frequencies: half of the mesocosms per depth treatment were randomly assigned to either i) a control irrigation frequency ('IRG'), in which each rewetting event was followed by a 31-45 day period of natural desiccation; or ii) a reduced irrigation frequency ("DRO"), in which mesocosms were subjected to longer desiccation periods (i.e. only rewetted on every third IRG rewetting event). The IRG treatment corresponded to $250 \mathrm{~mm}$ precipitation year ${ }^{-1}$, representing semiarid-to-arid climate conditions according to the Köppen-Geiger classification (Peel et al., 2007).

\subsection{Measurement of $\mathrm{CO}_{2}$-C efflux and Birch effects from topsoil horizons}

We measured daily total and ${ }^{14} \mathrm{C}$-labelled $\mathrm{CO}_{2}$ effluxes in two randomly selected mesocosms per depth and rewetting treatment $(n=2)$, using alkali traps $(10 \mathrm{ml} 0.5 \mathrm{M} \mathrm{NaOH}$; Casals et al., 2000), which were sealed with air-tight lids for $24 \mathrm{~h}$ to create a closed chamber above the soil profiles (Figure 1). To calculate the ${ }^{14} \mathrm{CO}_{2}$ efflux derived from wheat straw, we mixed two aliquots of alkali ( $1 \mathrm{ml}$ each) with $10 \mathrm{ml}$ scintillation cocktail (Ultima Gold ${ }^{\mathrm{TM}}$, PerkinElmer) and counted scintillations for 10 min using a scintillation counter (Packard Tri-carb 2100 TR; ${ }^{14} \mathrm{C}$-counting efficiency c. 95\%), which was periodically standardized (Transformed External Standard Spectrum method using $133 \mathrm{Ba}$ ). We used the remaining alkali to quantify total $\mathrm{CO}_{2}-$ $\mathrm{C}$ by back-titration with $0.25 \mathrm{M} \mathrm{HCl}$ after addition of $\mathrm{BaCl}_{2}$ in excess (Black, 1965). To account for soil respiration from the mineral subsoil, we installed twelve 'blank' mesocosms without topsoil horizon (six per rewetting treatment). The blank mesocosms were subjected to identical installation, conditions and measurement procedures as the mesocosms containing the labelled topsoil. Daily total- and ${ }^{14} \mathrm{C}-\mathrm{CO}_{2}$ effluxes from topsoil horizons were then calculated by subtracting the mean respiration rate of the blank mesocosms each day $(n=2)$ from the respiration rate of the labelled mesocosms. Although we measured $\mathrm{CO}_{2}$ efflux from all mesocosms, the $\mathrm{CO}_{2}$ data for subsurface mesocosms was discarded as mass balance calculations revealed a low $\mathrm{CO}_{2}-\mathrm{C}$ recovery from these mesocosms (only 86-97\%; data not shown).

At each rewetting event, alkali traps were installed 5 minutes after the end of the irrigation process. The mesocosms were normally left open for at least 3-4 days between measurements to allow evaporation. $\mathrm{CO}_{2}$ measurements were performed on 135 days of the 366-day irrigation period, with measuring days mainly allocated after rewetting events to capture soil respiration peaks, and measurement intervals during periods of low, stabilized respiration rates; Figure 2). For those days in which soil respiration was not measured, we estimated daily topsoil $\mathrm{CO}_{2}$ effluxes by linear interpolation (Casals et al., 2009). Volumetric soil water content (SWC) was measured in conjunction with $\mathrm{CO}_{2}$ measurements in dedicated equivalent (but unlabelled) 
mesocosms subjected to the same conditions, with side holes for moisture sensors (Thetaprobe, Delta-T, Cambridge, UK).

Cumulative total and labelled $\mathrm{CO}_{2}$ efflux from topsoil horizons was calculated from the mean of $n=2$ mesocosms at each measurement date, using cumulative maximum and minimum daily $\mathrm{CO}_{2}$ efflux as standard errors. In line with previous studies, the amount of organic $\mathrm{C}$ released by the Birch effect at each irrigation event was considered to be the cumulative $\mathrm{CO}_{2}-\mathrm{C}$ efflux from the topsoil horizon during the first three days upon rewetting (Franzluebbers et al., 2000; Kim et al., 2012). The overall amount of organic $\mathrm{C}$ released during the drying-rewetting cycle was considered to be the cumulative $\mathrm{CO}_{2}-\mathrm{C}$ efflux from the topsoil horizon during the first 31 days upon rewetting, after which soil respiration was negligible.

\subsection{Destructive sampling and gravimetric SWC}

We harvested three replicate mesocosms per depth and irrigation treatment immediately before the rewetting events in May 2007, September 2007 and January 2008, and four replicates in the January 2007 rewetting event (Table 1). The topsoil horizons were carefully separated from the mineral subsoil and the outermost part of each horizon was removed to discard 'edge effects' from the mesocosm walls. Immediately after each harvest, we oven-dried topsoil subsamples at $65^{\circ} \mathrm{C}$ for $48 \mathrm{~h}$ to measure gravimetric soil water content (SWC).

\subsection{Microbial + extractable organic C fractions (FEC)}

We determined the amount of 'available' $\mathrm{C}$ (total and ${ }^{14} \mathrm{C}$-labelled) as the fumigation-extraction $\mathrm{C}$ (FEC), the sum of the microbial and extractable organic $\mathrm{C}$ fractions using the method of Vance et al. (1987). The FEC fraction is considered the readily-accessible C pool supporting microbial activity (Casals et al., 2009, 2011; Rovira et al., 2010). Briefly, fresh subsamples of the topsoil (20 g dry-weight equivalent) were fumigated for $24 \mathrm{~h}$ in the dark with ethanol-free chloroform $\left(\mathrm{CHCl}_{3}\right)$ inside a vacuum chamber, then extracted with $100 \mathrm{ml} 0.5 \mathrm{M} \mathrm{K}_{2} \mathrm{SO}_{4}$ by shaking for $60 \mathrm{~min}$, centrifuged and filtered following Jones and Willet (2006). Paired 20-g fresh subsamples were extracted without $\mathrm{CHCl}_{3}$-fumigation. 3-ml aliquots of both fumigated and non-fumigated extracts were then analysed colorimetrically at $600 \mathrm{~nm}$ for total organic $\mathrm{C}$, after dichromate oxidation at $155^{\circ} \mathrm{C}$ for $30 \mathrm{~min}$ (Nelson and Sommers, 1996). Straw-derived ${ }^{14} \mathrm{C}$ was measured by mixing $1-\mathrm{ml}$ aliquots of both fumigated and non-fumigated extracts with $10 \mathrm{ml}$ of scintillation cocktail and counting for $10 \mathrm{~min}$ (more details in Lopez-Sangil et al., 2013). The base-line ${ }^{14} \mathrm{C}$ signature of the daily 'blank' respiration measurements was then subtracted. Microbial biomass C (MBC) was calculated as the difference between fumigated and non-fumigated organic $\mathrm{C}$ in the extracts (values not corrected for extraction efficiency unless stated otherwise; Vance et al., 1987). Total and labelled soil amounts were calculated after accounting for aliquot and soil sample sizes. The relative contribution of MBC to the total 'available' $\mathrm{C}$ pool was calculated as the ratio between MBC and FEC (MBC:FEC).

\subsection{Data analyses}


All data analyses were performed in R 3.2.3 ( $\mathrm{R}$ Core Team 2017). First, we assessed the influence of rewetting frequency treatment and soil temperature on $\mathrm{CO}_{2}$ or ${ }^{14} \mathrm{CO}_{2}$ released by three-day (Birch effect) and 31-day cumulative total or ${ }^{14} \mathrm{C}$-labelled $\mathrm{CO}_{2}$ efflux using linear mixed effects models with treatment, temperature, and their interaction as fixed effects and time as a random effect (lmer function in the lme4 package; Bates et al., 2015). We then assessed the effect of rewetting treatment on the FEC fraction and MBC:FEC ratio in the topsoil horizons using nested linear mixed effects models including treatment, horizon depth and their interaction as fixed effects, and sampling time as a random effect. Nested models were compared using the Akaike Information Criterion (AIC) and $p$-values and simplified by sequentially dropping terms until a minimum adequate model was reached (Pinheiro and Bates, 2000). Statistics are given for the comparison between the final models and the corresponding null model and individual terms are reported as significant at $p<0.05$. Finally, we used linear regression to assess the relationships between soil water content (SWC) and MBC:FEC ratio, and to test whether the magnitude of Birch effects (three-day cumulative $\mathrm{CO}_{2}$ ) was related to the amounts of 'available' $\mathrm{C}$ prior to rewetting (FEC, microbial and extractable organic $\mathrm{C}$ fractions were tested separately; measurements and samples taken in Jan-07, May-07 and Sep$07 ; n=5)$.

\section{Results}

\subsection{Birch effect and total $\mathrm{CO}_{2}-\mathrm{C}$ effluxes from surface horizons}

The release of $\mathrm{CO}_{2}$ by Birch effects (three-day efflux after rewetting) was strongly influenced by rewetting treatment and temperature for both $\mathrm{SOM}$-derived $\mathrm{CO}_{2}$ and straw-derived ${ }^{14} \mathrm{CO}_{2}$ $\left(\mathrm{CO}_{2}: \chi^{2}=54.7, p<0.001 ;{ }^{14} \mathrm{CO}_{2}: \chi^{2}=62.4, p<0.001\right)$. There was a significant interaction between treatment and temperature for ${ }^{14} \mathrm{CO}_{2}$ Birch effect efflux $(p=0.002)$ but not for SOMderived $\mathrm{CO}_{2}$. The magnitude of Birch effects was clearly greatest in the DRO treatment, with a lower rewetting frequency (Figure 3A, B).

The total amount of $\mathrm{SOM}$-derived $\mathrm{CO}_{2}$ released upon rewetting (31-day cumulative $\mathrm{CO}_{2}$ ) was mainly influenced by treatment, but temperature also had a marginal effect ( $p=0.07)$, Figure $3 \mathrm{C})$ and the final model included both treatment and temperature but not their interaction $\left(\chi^{2}=\right.$ 26.4, $p<0.001)$. 31-day cumulative ${ }^{14} \mathrm{CO}_{2}$ efflux was also strongly influenced by treatment $\left(\chi^{2}\right.$ $=42.8, p<0.001)$ but not soil temperature $(p=0.540)$, despite differences of $c .15^{\circ} \mathrm{C}$ between the rewetting events (Figure 3D). Interestingly, for the first two rewetting events, the 31-day cumulative ${ }^{14} \mathrm{CO}_{2}$ effluxes were near identical for IRG $(4.7 \pm 0.2$ and $3.3 \pm 0.1)$ and DRO treatments ( $4.7 \pm 0.2$ and $3.5 \pm 0.1$, respectively), despite the differences in rewetting frequency and seasonal pedoclimatic conditions (Figures 3D, 2D). The flux values declined with increasing number of rewetting events (Figure 3D).

In May to September, when soil desiccation at surface horizons was more severe (Table 1), the evolution of the daily soil $\mathrm{CO}_{2}$ efflux rates followed an exponential decay pattern, in which respiration rates were highest on the first day after rewetting but declined sharply and remained low until the next rewetting (Figures 2A, B). This pattern was much less distinct during the coldest seasons, when desiccation was less extreme (Figures 2A, B; Table 1). The magnitude 
of the Birch effects was strongly determined by soil desiccation levels (Figure 4). The $\mathrm{CO}_{2}$ released in the first 3 days upon rewetting, as a proportion of the total (monthly) $\mathrm{CO}_{2}$ efflux, was negatively related to soil water contents before rewetting, both for SOM- and plant litterderived $\mathrm{C}$ respiration $\left(R^{2}=0.85, p<0.001\right)$. This indicates that the peak in microbial respiration was greater, and its subsequent exponential decline steeper, when soils were drier prior to rewetting. Including both IRG and DRO treatments ensured that this effect was not simply driven by differences in temperature throughout the year.

\subsection{Microbial biomass and extractable organic $C$}

The depth of the topsoil horizon in the profile significantly influenced the pre-wetting levels of available $\mathrm{C}$ (FEC) derived from bulk $\operatorname{SOM}\left(\chi^{2}=7.87, p=0.005\right)$ but there was no overall effect of the rewetting frequency treatment (Figure 5). SOM-derived FEC levels in the surface horizon tended to increase steadily throughout the successive drying-rewetting cycles, regardless of treatment, whereas they decreased in the subsurface horizon (Figure 5A). In contrast, FEC derived from ${ }^{14} \mathrm{C}$-labelled straw was influenced by both rewetting frequency and depth, but not their interaction $\left(\chi^{2}=460.3, p<0.001\right.$; treatment effect $p<0.001$; depth effect $\left.=p<0.001\right)$. The subsurface horizons had higher pre-wetting levels of ${ }^{14} \mathrm{C}$-labelled FEC at the beginning of the irrigation period, but they showed greater depletion over time compared to the surface in both treatments. The decrease in both horizons was greater in the IRG compared to the DRO treatment, resulting in higher concentrations of ${ }^{14} \mathrm{C}$-labelled FEC in the DRO mesocosms by the end of the experiment (Figure 5B). The relative proportion of straw-derived ${ }^{14} \mathrm{C}$ in the FEC fractions was more than two-fold higher that the proportion of SOM-derived FEC at the beginning of the experiment (Figure 5), indicating rapid incorporation of fresh plant litter compounds into the most active soil $\mathrm{C}$ fractions. This difference disappeared during the summer as labile, straw-derived compounds were rapidly depleted by microbial mineralization.

Both rewetting frequency and horizon depth had a strong influence on soil microbial biomass during the drought periods. The relative contribution of SOM-derived microbial biomass $\mathrm{C}$ to the FEC fraction (MBC:FEC) was greater in the IRG compared to the DRO mesocosms, and in the subsurface horizons compared to the surface $\left(\chi^{2}=68.31, p<0.001\right)$. There was a significant treatment $\times$ depth interaction $(p=0.019)$, as the MBC:FEC ratio was higher in the subsurface horizons of the IRG (and the difference between horizon depths was greater) than in the DRO mesocosms. For straw-derived ${ }^{14} \mathrm{C}\left(\chi^{2}=68.31, p<0.001\right)$, there was a similar significant effect of treatment $(p=0.037)$ and depth $(p<0.001)$ but no interaction. The strong effect of depth on MBC:FEC can be explained by more severe desiccation in the surface horizons between rewetting events: MBC:FEC declined significantly with gravimetric soil water content for both SOM- and straw-derived C $\left(R^{2}=0.63, p<0.001\right.$ and $R^{2}=0.43, p<0.001$, respectively; Figure 6 ), indicating that living soil microorganisms represented a decreasing part of the FEC fraction as the soil desiccated. Contrary to expectations, we found no relationships $(p>0.1)$ between the magnitude of Birch effects and any of the soil $\mathrm{C}$ fractions deemed readily accessible to microbes immediately prior to rewetting (microbial biomass $\mathrm{C}$, extractable organic $\mathrm{C}$ or overall FEC contents; January, May and September events, $n=5$ ) for both SOM- and straw-derived C. 


\section{Discussion}

\subsection{Decomposition of organic C substrates and frequency of rewetting events}

The greatest Birch effects were observed after extended drought periods (DRO treatment) and during the warmer season (Figure 3). Seasonal temperature variation had a strong influence on the magnitude of the Birch effect (Figure 3), which is likely a result of 1) greater water evaporation at higher temperatures, which accelerates soil desiccation and exacerbates drought; and 2) increased microbial activity upon rewetting, as higher temperatures promote more rapid mineralization of organic substrates (Davidson and Janssens, 2006). At higher temperatures, the combination of increased soil desiccation and microbial activity results in larger short-term C losses from soils (Chowdhury et al., 2011). It is possible that a small proportion of the observed Birch effects was derived from inorganic sources, as result of the increase in soil pore water and $\mathrm{CO}_{2}$ (lower $\mathrm{pH}$ ) associated with rewetting and microbial respiration (Emmerich, 2003; Stevenson and Verburg, 2006). In a calcareous soil with similar organic:inorganic C ratio, Stevenson and Verburgh (2006) found that up to $13 \%$ of total soil $\mathrm{CO}_{2}-\mathrm{C}$ efflux was derived from soil carbonates. By contrast, soil rewetting did not significantly increase inorganic $\mathrm{CO}_{2}$ effluxes from different Mediterranean calcareous soils (Inglima et al., 2009). Similarly, in our study, the potential contribution of soil carbonates to the observed Birch effects was deemed negligible. Firstly, mass balance calculations of the topsoil SOC respired, leached and remaining always produced 99 to $101 \% \mathrm{C}$ across samplings $(100.1 \pm 0.3 \%)$. Secondly, direct measurements on the topsoil horizons showed a high stability of the soil carbonates equilibrium during the incubation period, with negligible further incorporation of litter-derived ${ }^{14} \mathrm{CO}_{2}$ into carbonates (Lopez-Sangil et al., 2013).

The frequency of rainfall events is crucial for soil carbon dynamics in arid and semiarid ecosystems. In support of our second hypothesis, our results indicate that forecast scenarios of infrequent heavy rainfalls and longer drought periods (IPCC, 2013; Prein et al., 2016) will have a greater impact on the decomposition of recent plant litter compared to that of more stable SOM (Figures 2D, 3). This is in line with Magid et al. (1999), who found that drying-rewetting conditions in lab soil incubations retarded the mineralization of fresh plant litter (but not SOM) compared to constantly moist soils. Interestingly, in our study soil temperature did not affect the overall amount of straw-derived ${ }^{14} \mathrm{C}$ respired during the month after rewetting, despite the positive influence of temperature on the magnitude of Birch effects. Instead, the mineralization of plant litter during each drying-rewetting cycle was only related to the number of previous rewetting events, resulting in nearly identical amounts of $\mathrm{CO}_{2}-{ }^{14} \mathrm{C}$ released after the same number of irrigations, despite seasonal temperature differences of $15^{\circ} \mathrm{C}$ (Figure 3D). Our results contrast with the general relationship between temperature and plant litter decomposition in soils (Davidson and Janssens, 2006), and with the temperature effects observed on the shortterm ${ }^{14} \mathrm{CO}_{2}$ release upon rewetting. Using the magnitude of short-term respiration flushes as a proxy for soil $\mathrm{C}$ mineralization and quality (Franzluebbers et al., 2000) may therefore be inappropriate, especially for organic matter recently incorporated into soils.

\subsection{Soluble and microbial organic C fractions, and their relation to $\mathrm{CO}_{2}$ efflux}


The pattern of declining Birch effects with increasing number of drying-rewetting cycles (Figures 2, 3) has also been observed in other studies (Casals et al., 2009; Mikha et al., 2005; Wu and Brookes, 2005). Although a gradual depletion of available C (FEC) has been proposed as the main reason for this decline over time (Casals et al., 2009), we found no evidence to support our hypothesis that the magnitude of Birch effects was related to pre-existing soil microbial or extractable organic $\mathrm{C}$ contents before rewetting. Others have questioned whether the organic solutes present within the soil matrix constitute a major $\mathrm{C}$ source for microbial respiration (De Troyer et al., 2011). It has been shown that the extractable organic $\mathrm{C}$ fraction can remain unchanged despite large increases in soil respiration (Xiang et al., 2008), casting doubts about its biodegradability. Moreover, large proportions of dissolved OM (up to 85\%) can remain in incubated soils for several months (Zsolnay and Steindl, 1991; Qualls and Haines, 1992). Instead, it is possible that a significant part of the FEC fraction is not easily-degradable, and that labile $\mathrm{C}$ solutes pass rapidly through the extractable pool before being mineralized (De Troyer et al., 2011; Xiang et al., 2008). Our results suggest that $\mathrm{C}$ sources other than the microbial and $\mathrm{K}_{2} \mathrm{SO}_{4}$-extractable organic $\mathrm{C}$ fractions were mineralized during the Birch effect pulses in this experiment.

Extreme soil desiccation (and subsequent rewetting) events can destabilize SOM protection mechanisms and release organic solutes into the media (Borken and Matzner, 2009). The severe drying-rewetting conditions in our experiment stimulated the incorporation of SOM-derived organic solutes into the FEC fraction at surface horizons (Figure 5A) and this increase occurred despite an overall decrease in SOM content during the incubation period (Lopez-Sangil et al., 2013). Two mechanisms could trigger this FEC replenishment in our experiment: i) SOMmineral detachments, involving either chemical desorption of soluble and colloidal OM (LopezSangil and Rovira, 2013) or physical disruption of aggregates (Denef et al., 2001), which expose new organic surfaces to microbes; and ii) microbial breakdown of free organic particles by microbial enzymatic activity (Burns et al., 2013). Both mechanisms are likely to be promoted by a higher recurrence of soil drying-rewetting cycles: SOM-mineral detachments are induced by the physical forces during the drying and/or rewetting phases (Denef et al., 2001; Xiang et al., 2008), whereas more frequent rewetting events allow for longer periods of microbial activity. Accordingly, soil respiration in our study was greater in the IRG compared to DRO treatment (Figures 2C, D; Figure 3), but we only found evidence of FEC replenishment when topsoil was incubated at surface (Figure 5), where desiccation and rewetting phases were more intense and abrupt. The gradual decrease in ${ }^{14} \mathrm{C}$ within the FEC fraction (Figure 5B) evidences the progressive depletion of the initial litter inputs (Lopez-Sangil et al., 2013), but can also result from a preferential consumption of these easily-degradable compounds by soil microbes (De Troyer et al., 2011), which can lead to a gradual increase in FEC recalcitrance as soil desiccation progresses. Together, these findings support the idea that these 'available' $\mathrm{C}$ fractions in desiccated soils, which have been proposed as a primary source of $\mathrm{C}$ for subsequent Birch effects (Wang et al., 2003; Casals et al., 2009), may be mainly composed of SOMderived, relatively recalcitrant substrates.

\subsection{Mechanisms underlying Birch effects}


The observed Birch effects could not be predominantly attributed to any one of the other commonly proposed mechanisms. Microbial cell lysis and/or osmoregulation have been proposed as the main C source of Birch effects in agricultural soils (Mikha et al., 2005), grassland soils (Warren, 2016) and Mediterranean dehesa (Unger et al., 2010), although other D-RW studies found no evidence for this (Williams and Xia, 2009; Boot et al., 2013). In our study, microbial biomass was severely reduced during extreme drought, as indicated by the decline in the proportion of $\mathrm{MBC}$ within the FEC fraction (Figure 6). However, only the $\mathrm{CO}_{2}-$ $\mathrm{C}$ released during the first day upon rewetting accounted for more than $90 \%$ of the pre-wetting levels of FEC (May-2007, DRO mesocosms), and more than $60 \%$ of the microbial biomass C (Sep-2007; corrected for extraction efficiency, Vance et al., 1987), for both SOM- and strawderived $\mathrm{C}$, which is substantially higher than the estimated maximum osmolyte $\mathrm{C}$ concentrations of c. $10 \%$ and up to $30-40 \%$ in soil fungi and bacteria (Schimel et al., 2007). Finally, the spatial redistribution of existing organic solutes and/or microbes upon rewetting could not explain the respiration pulses observed in our study, as it depends largely on FEC levels at the time of rewetting (Van Gestel et al., 1993; Xiang et al., 2008) and we found no relationship between FEC, extractable $\mathrm{C}$ and Birch effects. These lines of evidence do not exclude microbial lysis and/or osmorregulatory mechanisms, but show they are insufficient to explain the magnitude of the observed $\mathrm{CO}_{2}-\mathrm{C}$ pulses during the first three days after rewetting. Instead, other authors have highlighted the relevance of physical disturbance on soil aggregates in driving the Birch effect pulses (Navarro-Garcia et al., 2012), suggesting that additional mechanisms (such as remnant exoenzymatic activity, Fraser et al., 2016) may contribute to the respiration of the newly-exposed organic surfaces. These substrate-supply mechanisms are in line with our FEC results in surface horizons (Figure 5). We propose that a great proportion of the observed $\mathrm{CO}_{2}$ pulses could originate from the physical disruption of organo-mineral surfaces during severe drying-rewetting conditions (Williams and Xia, 2009; Navarro-Garcia et al., 2012), exposing a plethora of new organic substrates that would be rapidly and preferentially consumed by microbes depending on their decomposability, leading to an increased recalcitrance of the soluble $\mathrm{C}$ fraction as desiccation progresses.

In contrast to our study, previous work in a Mediterranean dehesa (Casals et al., 2009; 2011) found evidence that Birch effect was related to the pre-wetting FEC contents. We suggest that this discrepancy arises from: i) differences in soil structure between the dehesa $(80 \%$ sand, $9 \%$ clay) and the topsoil in this experiment (41\% sand, $31 \%$ clay) resulting in lower organo-mineral protection (Lopez-Sangil and Rovira, 2013), aggregate stability and microporosity in the dehesa soil, which would affect the contribution of non-biomass SOM to post-rewetting respiration peaks (Van Gestel et al., 1993); and ii) the absence of plant roots in our study, as fine-root rhizodeposition constitute an important input of fresh labile $\mathrm{C}$ into the FEC fraction during droughts (Yao et al., 2012; Preece and Peñuelas, 2016), which can fuel pulses of microbial respiration upon rewetting. This was already suggested as an explanation to similar discrepancies between lab and field experiments, in which no correlation was found between soluble organic $\mathrm{C}$ and soil mineralization processes upon rewetting (Lundquist et al., 1999).

\subsection{Conclusions}


In response to severe soil drying-rewetting conditions, we observed a gradual increase in SOMderived organic solutes, and a significant decrease in microbial biomass size. However, although osmoregulation or pre-wetting availability of soil organic solutes may contribute to Birch effects, we found little evidence to support the hypotheses that they are the main carbon sources determining the magnitude of the soil $\mathrm{CO}_{2}$ flushes during Birch effects. Birch effects derived from both SOM and fresh litter sources were positively correlated with seasonal fluctuations in temperature. But in terms of overall $\mathrm{CO}_{2}-\mathrm{C}$ release during the entire dryingrewetting cycle, only the efflux derived from SOM decomposition, and not that from fresh litter, was positively related to temperature. Our results highlight differences in the mechanisms controlling post-rewetting soil respiration depending on the $\mathrm{C}$ source, and emphasize the need for improving our understanding of soil $\mathrm{C}$ mineralization at different time-scales and under variable climatic conditions. Further work is needed to clarify how soil disruption by repeated drying-rewetting cycles contributes to the release of new organic solutes, as this could accelerate SOC depletion in dryland ecosystems (Xiang et al., 2008; Casals et al., 2009).

\section{Acknowledgements}

This study was partially funded by the Spanish Research Agency (MEC: VULCA, CGL200508133-CO2). Luis Lopez-Sangil had a pre-doctoral fellowship (APIF 2008-2012; 00154) from the University of Barcelona, and was granted with a short-stay fellowship at the University of Exeter by the ESF-funded MOLTER program. Both Pere Rovira and Pere Casals have a I3 post-doctoral grant from the Spanish Ministry of Science and Innovation. E. J. Sayer was supported by a European Research Council Starting Grant under the European Union's Seventh Framework Programme (FP/2007-2013; ERC Grant Agreement No. 307888).

\section{Data statement}

The data Masterfile, including the data used in statistical tests and the raw soil $\mathrm{CO}_{2}$ efflux datasets, will be uploaded in an online open-access data repository upon acceptance of the manuscript for publication.

\section{References}

Bapiri, A., Bååth, E., Rousk, J., 2010. Drying-rewetting cycles affect fungal and bacterial growth differently in an arable soil. Microbial Ecology, 60, 419-428.

Bates, D., Machler, M., Bolker, B.M., Walker, S.C., 2015. Fitting Linear Mixed-Effects Models Using lme4. Journal of Statistical Software, 67, 1-48.

Birch, H.F., 1958. The effect of soil drying on humus decomposition and nitrogen availability. Plant and Soil, 10, 9-31.

Black, C.A., 1965. Methods of Soil Analysis: Part 2. American Society of Agronomy, Inc. publisher, Madison, pp. 1562-1565. 
Boot, C.M., Schaeffer, S.M., Schimel, J.P., 2013. Static osmolyte concentrations in microbial biomass during seasonal drought in a California grassland. Soil Biology and Biochemistry, 57, 356-361.

Borken, W., Matzner, E., 2009. Reappraisal of drying and wetting effects on C and N mineralization and fluxes in soils. Global Change Biology, 15, 808-824.

Bosatta, E., Agren, G.I., 1999. Soil organic matter quality interpreted thermodynamically. Soil Biology and Biochemistry, 31, 1889-1891.

Bottner, P., 1985. Response of microbial biomass to alternate moist and dry conditions in a soil incubated with ${ }^{14} \mathrm{C}$ - and ${ }^{15} \mathrm{~N}$-labelled plant material. Soil Biology and Biochemistry, 17, 329-337.

Boyer, J.N., Groffman, P.M., 1996. Bioavailability of water extractable organic carbon fractions in forest and agricultural soil profiles. Soil Biology and Biochemistry, 28, 783-790.

Burns, R.G., DeForest, J.L., Marxsen, J., Sinsabaugh, R.L., Stromberger, M.E., Wallenstein, M.D., Weintraub, M.N., Zoppini, A., 2013. Soil enzymes in a changing environment: current knowledge and future directions. Soil Biology and Biochemistry, 58, 216-234.

Cable, J.M., Ogle, K., Lucas, R.W., Huxman, T.E., Loik, M.E., Smith, S.D., Tissue, D.T., Ewers, B.E., Pendall, E., Welker, J.M., Charlet, T.N., Cleary, M., Griffith, A., Nowak, R.S., Rogers, M., Steltzer, H., Sullivan, P.F., van Gestel, N.C., 2011. The temperature responses of soil respiration in deserts: a seven desert synthesis. Biogeochemistry, 103, 71-90.

Casals, P., Romanyà, J., Cortina, J., Bottner, P., Coûteaux, M.M., Vallejo, V.R., 2000. $\mathrm{CO}_{2}$ efflux from a Mediterranean semi-arid forest soil. I. Seasonality and effects of stoniness. Biogeochemistry, 48, 261-281.

Casals, P., Gimeno, C., Carrara, A., Lopez-Sangil, L., Sanz, M.J., 2009. Soil CO 2 efflux and extractable organic carbon fractions under simulated precipitation events in a Mediterranean Dehesa. Soil Biology and Biochemistry, 41, 1915-1922.

Casals, P., Lopez-Sangil, L., Carrara, A., Gimeno, C., Nogués, S., 2011. Autrotrophic and heterotrophic contributions to short-term soil $\mathrm{CO}_{2}$ efflux following simulated summer precipitation pulses in a Mediterranean dehesa. Global Biogeochemical Cycles, 25, GB3012.

Chowdhury, N., Yan, N., Islam, M.N., Marschner, P., 2011. The extent of drying influences the flush of respiration after rewetting in non-saline and saline soils. Soil Biology and Biochemistry, 43, 22652272 .

Coleman, K., Jenkinson, D.S., 1996. RothC-26.3 - a model for the turnover of carbon in soil. In: Powlson, D.S., Smith, P., Smith, J.U. (eds.), Evaluation of soil organic matter models, NATO ASI Series, vol. I 38, Springer, Berlin, pp. 237-246.

Davidson, E., Janssens, I., 2006. Temperature sensitivity of soil carbon decomposition and feedbacks to climate change. Nature, 440, 165-173.

Denef, K., Six, J., Paustian, K., Merchkx, R., 2001. Importance of macroaggregate dynamics in controlling soil carbon stabilization: short-term effects of physical disturbance induced by dry-wet cycles. Soil Biology and Biochemistry, 33, 2145-2153.

De Troyer, I., Amery, F., Van Moorleghem, C., Smolders, E., Merckx, R., 2011. Tracing the source and fate of dissolved organic matter in soil after incorporation of a ${ }^{13} \mathrm{C}$ labelled residue: A batch incubation study. Soil Biology and Biochemistry 43, 513-519.

Emmerich, W.E., 2003. Carbon dioxide fluxes in semiarid environment with high carbonate soils. Agricultural and Forest Meteorology, 116, 91-102. 
Falloon, P., Jones, C.D., Ades, M., Paul, K., 2011. Direct soil moisture controls of future global soil carbon changes: an important source of uncertainty. Global Biogeochemical Cycles, 25, GB3010.

Fierer, N., Schimel, J., 2003. A proposed mechanism for the pulse in carbon dioxide production commonly observed following the rapid rewetting of a dry soil. Soil Science Society of America Journal, 67, 798-805.

Franzluebbers, A.J., Haney, R.L., Honeycutt, C.W., Schomberg, H.H., Hons, F.M., 2000. Flush of carbon dioxide following rewetting of dried soil relates to active organic pools. Soil Science Society of America Journal, 64, 613-623.

Fraser, F.C., Corstanje, R., Deeks, L.K., Harris, J.A., Pawlett, M., Todman, L.C., Whitmore, A.P., Ritz, K., 2016. On the origin of carbon dioxide released from rewetted soils. Soil Biology and Biochemistry, 101, 1-5.

Gordon, H., Haygarth, P.M., Bardgett, R. D., 2008. Drying and rewetting effects on soil microbial community composition and nutrient leaching. Soil Biology and Biochemistry, 40, 302-311.

Guenet, B., Neill, C., Bardoux, G., Abbadie, L., 2010. Is there a linear relationship between priming effect intensity and the amount of organic matter input? Applied Soil Ecology, 46, 436-442.

Halverson, L.J., Jones, T.M., Firestone, M.K., 2000. Release of intracellular solutes by four soil bacteria exposed to dilution stress. Soil Science Society of America Journal, 64, 1630-1637.

Inglima, I., Alberti, G., Bertolini, T., Vaccari, P., Gioli, B., Miglietta, F., Cotrufo, M.F., Peressotti, A., 2009. Precipitation pulses enhance respiration of Mediterranean ecosystems: the balance between organic and inorganic components of increased soil $\mathrm{CO}_{2}$ efflux. Global Change Biology, 15, 12891301.

Intergovernmental Panel on Climate Change, in: Climate Change 2013: The Physical Science Basis. Contribution of Working Group I to the Fifth Assessment Report of the Intergovernmental Panel on Climate Change, T. F. Stocker et al., Eds. (Cambridge Univ. Press, 2013), pp. 3-29.

IUSS Working Group WRB, 2006. World reference base for soil resources 2006. 2nd edition. World Soil Resources Reports No. 103. FAO, Rome.

Jarvis, P., Rey, A., Petsikos, C., Wingate, L., Rayment, M., Pereira, J., Banza, J., David, J., Miglietta, F., Borghetti, M., Manca, G., Valentini, R., 2007. Drying and wetting of Mediterranean soils stimulates decomposition and carbon dioxide emission: the "Birch effect". Tree physiology, 27, 929-940.

Jones, D.L., Willet, V.B., 2006. Experimental evaluation of methods to quantify dissolved organic nitrogen (DON) and dissolved organic carbon (DOC) in soil. Soil Biology and Biochemistry, 38, 991-999.

Kalbitz, K., Solinger, S., Park, J.H., Michalzik, B., Matzner, E., 2000. Controls on the dynamics of dissolved organic matter in soils: a review. Soil Science, 165, 277-304.

Kieft, T., Soroker, E., Firestone, M., 1987. Microbial biomass response to a rapid increase in water potential when dry soil is wetted. Soil Biology and Biochemistry, 19, 119-126.

Kim, D.G., Vargas, R., Bond-Lamberty, B., Turetsky, M.R., 2012. Effects of soil rewetting and thawing on soil gas fluxes: a review of current literature and suggestions for future research. Biogeosciences, 9, 2459-2483. 
Kjaergaard, C., Hansen, H.C.B., Koch, C.B., Villholth, K.G., 2004. Properties of water-dispersible colloids from macropore deposits and bulk horizons of an Agrudalf. Soil Science Society of America Journal, 68, 1844-1852.

Lopez-Sangil, L., Rovira, P., 2013. Chemical extractions of the mineral-associated soil organic matter: an integrated approach for the fractionation of organo-mineral complexes. Soil Biology and Biochemistry, 62, 57 - 67.

Lopez-Sangil, L., Rovira, P., Casals, P., 2013. Decay and vertical allocation of organic C, and its incorporation into carbonates, in agricultural soil horizons at two different depths and rewetting frequencies. Soil Biology and Biochemistry, 61, 33-44.

Lundquist, E.J., Jackson, L.E., Scow, K.M., 1999. Wet-dry cycles affect dissolved organic carbon in two California agricultural soils. Soil Biology and Biochemistry, 31, 1031-1038.

Magid, J., Kjaergaard, C., Gorissen, A., Kuikman, P.J., 1999. Drying and rewetting of a loamy sand soil did not increase the turnover of native organic matter, but retarded the decomposition of added ${ }^{14} \mathrm{C}$ labelled plant material. Soil Biology and Biochemistry, 31, 595-602.

Mikha, M.M., Rice, C.W., Milliken, G.A., 2005. Carbon and nitrogen mineralization as affected by drying and wetting cycles. Soil Biology and Biochemistry, 37, 339-347.

Miller, A.E., Schimel, J. P., Meixner, T., Sickman, J. O., Melack, J. M., 2005. Episodic rewetting enhances carbon and nitrogen release from chaparral soils. Soil Biology and Biochemistry, 37, 2195-2204.

Navarro-Garcia, F., Casermeiro, M.A., Schimel, J.P., 2012. When structure means conservation:effect of aggregate structure in controlling microbial responses to rewetting events. Soil Biology and Biochemistry, 44, 1-8.

Nelson, D.W., Sommers, L.E., 1996. Total carbon, organic carbon, and organic matter. In: Sparks DL (ed.) Methods of soil analysis, Part 3: chemical methods, 3rd edn. SSSA Book Series 5, Madison, pp 961-1010.

Peel, M.C., Finlayson, B.L., McMahon, T.A., 2007. Updated world map of the Köppen-Geiger climate classification. Hydrology and Earth Sciences Discussions, European Geosciences Union, 4, 439473.

Pinheiro, J.C., Bates, D.M., 2000. Mixed-Effects Models in S and S-PLUS. Springer, New York.

Preece, C., Peñuelas, J., 2016. Rhizodeposition under drought and consequences for soil communities and ecosystem resilience. Plant and Soil, 409, 1-17.

Prein, A.F., Holland, G.J., Rasmussen, R.M., Clark, M.P., Tye, M.R., 2016. Running dry: The U.S. Southwest's drift into a drier climate state. Geophysical Research Letters, 43, 1272-1279.

Probert, M.E., Dimes, J.P., Keating, B.A., Dalal, R.C., Strong, W.M., 1998. APSIM's water and nitrogen modules and simulation of the dynamics of water and nitrogen in fallow systems. Agricultural Systems, 56, 1-28.

Qualls, R., Haines, B.L., 1992. Biodegradability of dissolved organic matter in forest throughfall, soil solution, and stream water. Soil Science Society of America Journal, 56, 578-586.

R Core Team, 2017. R: A Language and Environment for Statistical Computing. R Foundation for Statistical Computing, Vienna, Austria. https://www.R-project.org/. 
Rovira, P., Vallejo, V.R., 1997. Organic carbon and nitrogen mineralization under Mediterranean climatic conditions: the effects of incubation depth. Soil Biology and Biochemistry, 29, 1509-1520.

Rovira, P., Jorba, M., Romanyà, J., 2010. Active and passive organic matter fractions in Mediterranean forest soils. Biology and Fertility of Soils, 46, 355-369.

Sanaullah, M., Chabbi, A., Leifeld, J., Bardoux, G., Billou, D., Rumpel, C., 2011. Decomposition and stabilization of root litter in top- and subsoil horizons: what is the difference? Plant and Soil, 338, 127-141.

Sanaullah, M., Rumpel, C., Charrier, X., Chabbi, A., 2012. How does drought stress influence the decomposition of plant litter with contrasting quality in a grassland ecosystem? Plant and Soil, 352, 277-288.

Sato, A., Seto, M., 1999. Relationship between rate of carbon dioxide evolution, microbial biomass carbon, and amount of dissolved organic carbon as affected by temperature and water content of a forest and an arable soil. Communications in Soil Science and Plant Analysis, 30, 2593-2605.

Schimel, J., Balser, T.C., Wallenstein, M., 2007. Microbial stress-response physiology and its implication for ecosystem function. Ecology, 88, 1386-1394.

Shen, R.F., Brookes, P.C., Powlson, D.S., 1997. Effect of long-term straw incorporation on soil microbial biomass and $\mathrm{C}$ and $\mathrm{N}$ dynamics. Pedosphere, 7, 297-302.

Stevenson, B.A., Verburg, P.S.J. 2006. Effluxed $\mathrm{CO}_{2}-{ }^{13} \mathrm{C}$ from sterilized and unsterilized treatments of a calcareous soil. Soil Biology and Biochemistry, 38, 1727-1733.

Suseela, V., Conant, R.T., Wallenstein, M.D., Dukes, J.S., 2012. Effects of soil moisture on the temperature sensitivity of heterotrophic respiration vary seasonally in an old-field climate change experiment. Global Change Biology, 18, 336-348.

Unger, S., Máguas, C., Pereira, J.S., David, T.S., Werner, C., 2010. The influence of precipitation pulses on soil respiration - Assessing the "Birch effect" by stable carbon isotopes. Soil Biology and Biochemistry, 42, 1800-1810.

Vance, E.D., Brookes, P.C., Jenkinson, D.S., 1987. An extraction method for measuring soil microbial biomass C. Soil Biology and Biochemistry, 19, 703-707.

Van Gestel, M., Merckx, R., Vlassak, K., 1993. Microbial biomas and activity in soils with fluctuating water contents. Geoderma, 56, 617-626.

Wang, W.J., Dalal, R.C., Moody, P.W., Smith, C.J., 2003. Relationships of soil respiration to microbial biomass, substrate availability and clay content. Soil Biology and Biochemistry, 35, 273-284.

Warren, C.R., 2016. Do microbial osmolytes or extracellular depolymerisation products accumulate as soil dries? Soil Biology and Biochemistry, 98, 54-63.

Wetherald, R.T., Manabe, S., 2002. Simulation of hydrologic changes associated with global warming. Journal of Geophysical Research, 107(D19), 4379.

Williams, M.A., Xia, K., 2009. Characterization of the water soluble soil organic pool following the rewetting of dry soil in a drought-prone tallgrass prairie. Soil Biology and Biochemistry, 41, 2128.

$\mathrm{Wu}$, J., Brookes, P.C., 2005. The proportional mineralisation of microbial biomass and organic matter caused by air-drying and rewetting of a grassland soil. Soil Biology and Biochemistry, 37, 507515. 
Xiang, S.R., Doyle, A., Holden, P.A., Schimel, J.P., 2008. Drying and rewetting effects on C and N mineralization and microbial activity in surface and subsurface California grassland soils. Soil Biology and Biochemistry, 40, 2281-2289.

Yao, H.Y., Thornton, B., Paterson, E., 2012. Incorporation of ${ }^{13} \mathrm{C}$-labelled rice rhizodeposition carbon into soil microbial communities under different water status. Soil Biology and Biochemistry, 53, 72-77.

Zsolnay, A., Steindl, H., 1991. Geovariability and biodegradability of the water-extractable organic material in an agricultural soil. Soil Biology and Biochemistry, 23, 1077-1082. 
TABLE 1 Gravimetric soil water content (in water:soil weight $\% ; 65^{\circ} \mathrm{C}$ for $48 \mathrm{~h}$ ) of the agricultural soil horizons at the four destructive samplings (mean \pm SE; $n=3$ except for Jan/07: $n=4$ ).

\begin{tabular}{cccccc}
\hline & & Jan/07 & May/07 & Sep/07 & Jan/08 \\
\hline \multirow{2}{*}{$0-4 \mathrm{~cm}$} & IRG & \multirow{2}{*}{$6.6 \pm 0.3$} & $2.3 \pm 0.1$ & $2.2 \pm 0.1$ & $7.9 \pm 0.3$ \\
& DRO & & $1.8 \pm 0.0$ & $1.5 \pm 0.0$ & $2.5 \pm 0.0$ \\
\hline \multirow{2}{*}{$10-14 \mathrm{~cm}$} & IRG & \multirow{2}{*}{$11.3 \pm 0.1$} & $9.4 \pm 0.4$ & $9.7 \pm 0.3$ & $13.6 \pm 0.8$ \\
& DRO & & $4.1 \pm 0.1$ & $3.3 \pm 0.1$ & $4.6 \pm 0.1$ \\
\hline
\end{tabular}


FIGURE 1 Scheme of the mesocosms with the labeled agricultural topsoil horizons at $0-4 \mathrm{~cm}$ (surface level; left-hand diagram) and 10-14 cm depth (subsurface; right-hand diagram). The mineral subsoil fills the rest of the soil profile. An alkali trap measuring daily soil $\mathrm{CO}_{2}-\mathrm{C}$ effluxes from surface topsoil horizons is represented.
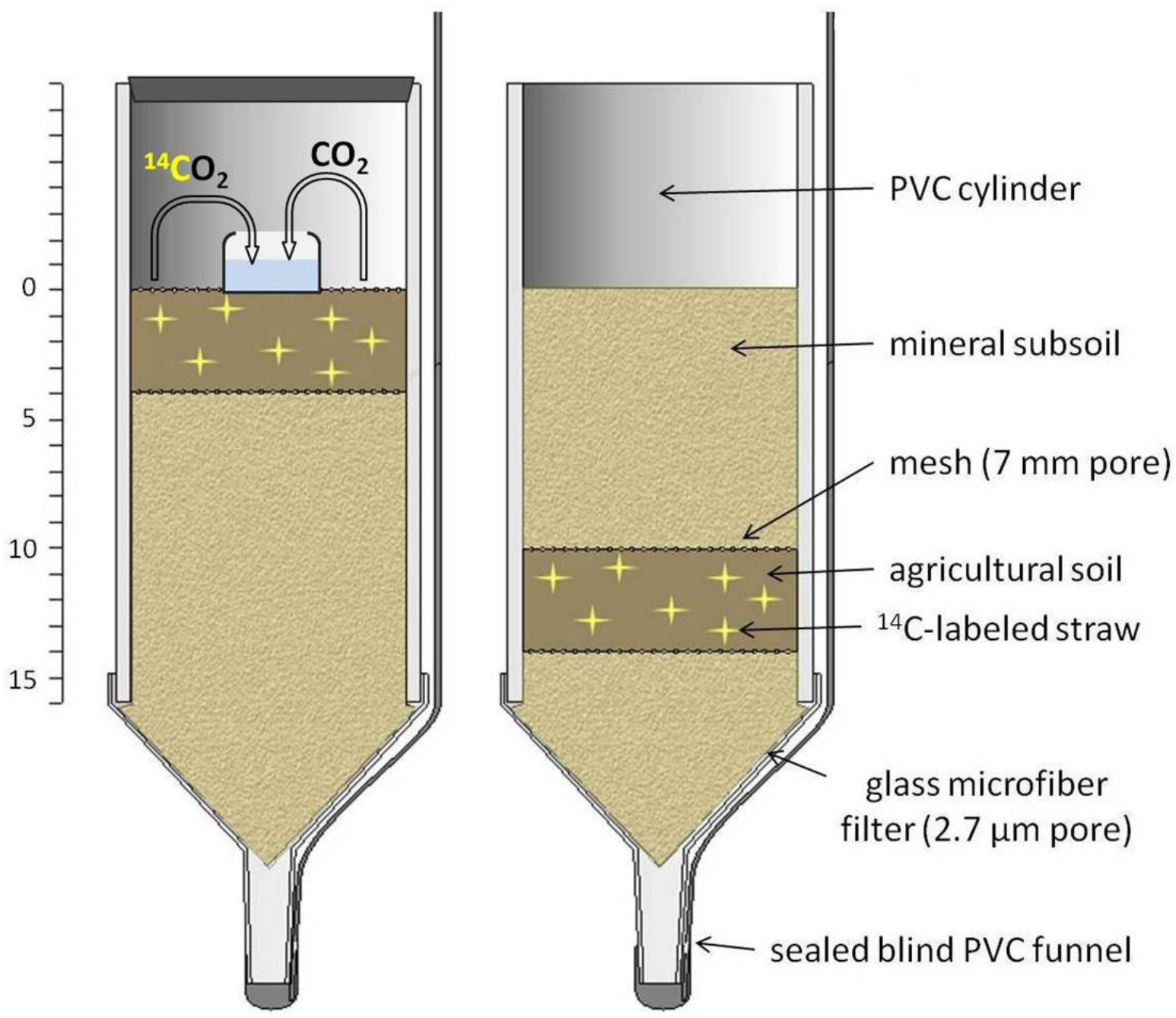
FIGURE $2 \mathrm{CO}_{2}-\mathrm{C}$ effluxes from the labelled topsoil horizons at surface level: $\mathbf{A}, \mathbf{B}$ ) daily respiration rates for total soil organic $C\left(T O C\right.$ ) and straw-derived ${ }^{14} \mathrm{C}$, respectively (mean $\pm S E ; n=2$ ); grey area represent daily mean soil temperature, with negligible differences between IRG and DRO treatments; red arrows indicate the four soil destructive sampling points. C, D) cumulative respiration for total soil organic C (TOC) and straw-derived 14C, respectively (mean \pm SE; cumulative error bars sparsely; $\mathrm{n}=2$ ); only those days in which $\mathrm{CO}_{2}$ measurements were performed are represented; the in-between days were calculated by linear interpolations. The 'irrigation period' extended from 15-Jan to 15-Jan (366 days), Data from the 'installation period' (Nov/06 to Jan/07) not shown.
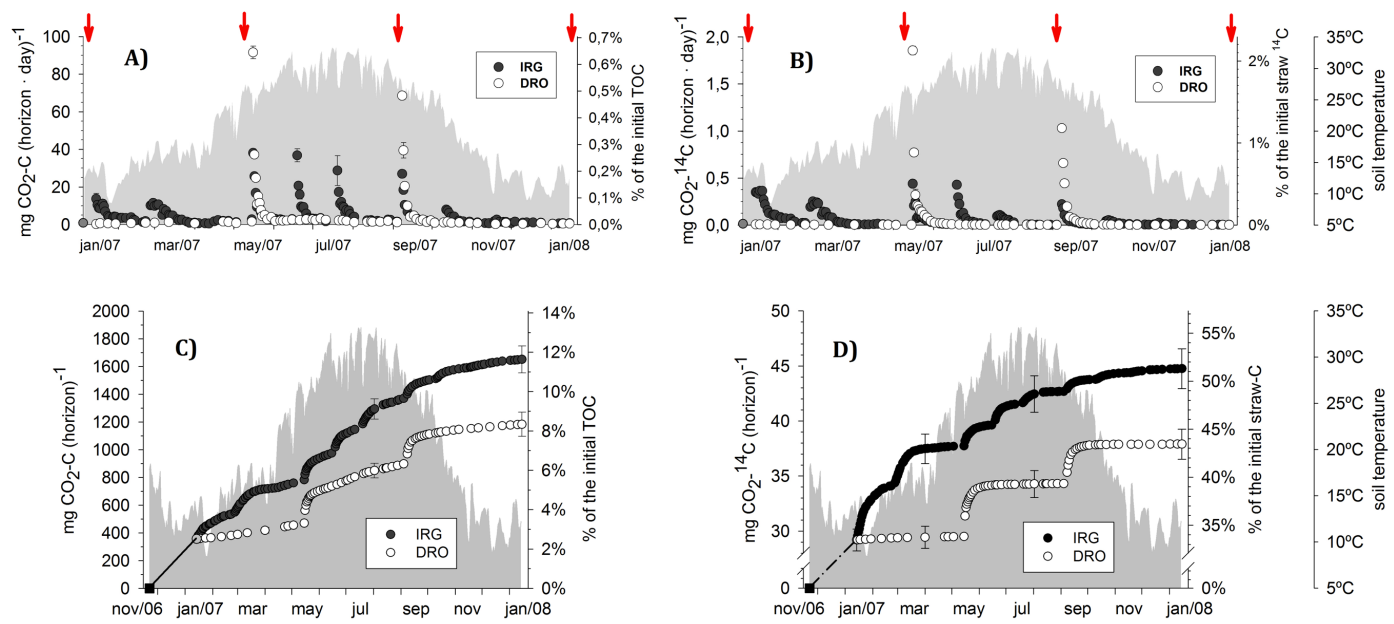
FIGURE 3 Cumulative $\mathrm{CO}_{2}$-C losses from soil microbial respiration at surface horizons (mean \pm SE; $\mathrm{n}=2$ ): A, B) first 3 days upon rewetting ("Birch effect"); C, D) 31 days upon rewetting. Left hand-side figures (hexagons) correspond to total, SOM-derived respiration, right hand-side figures (triangles) to straw-derived ${ }^{14} \mathrm{C}$ respiration. Grey areas represent the mean soil temperature for the assessed periods.
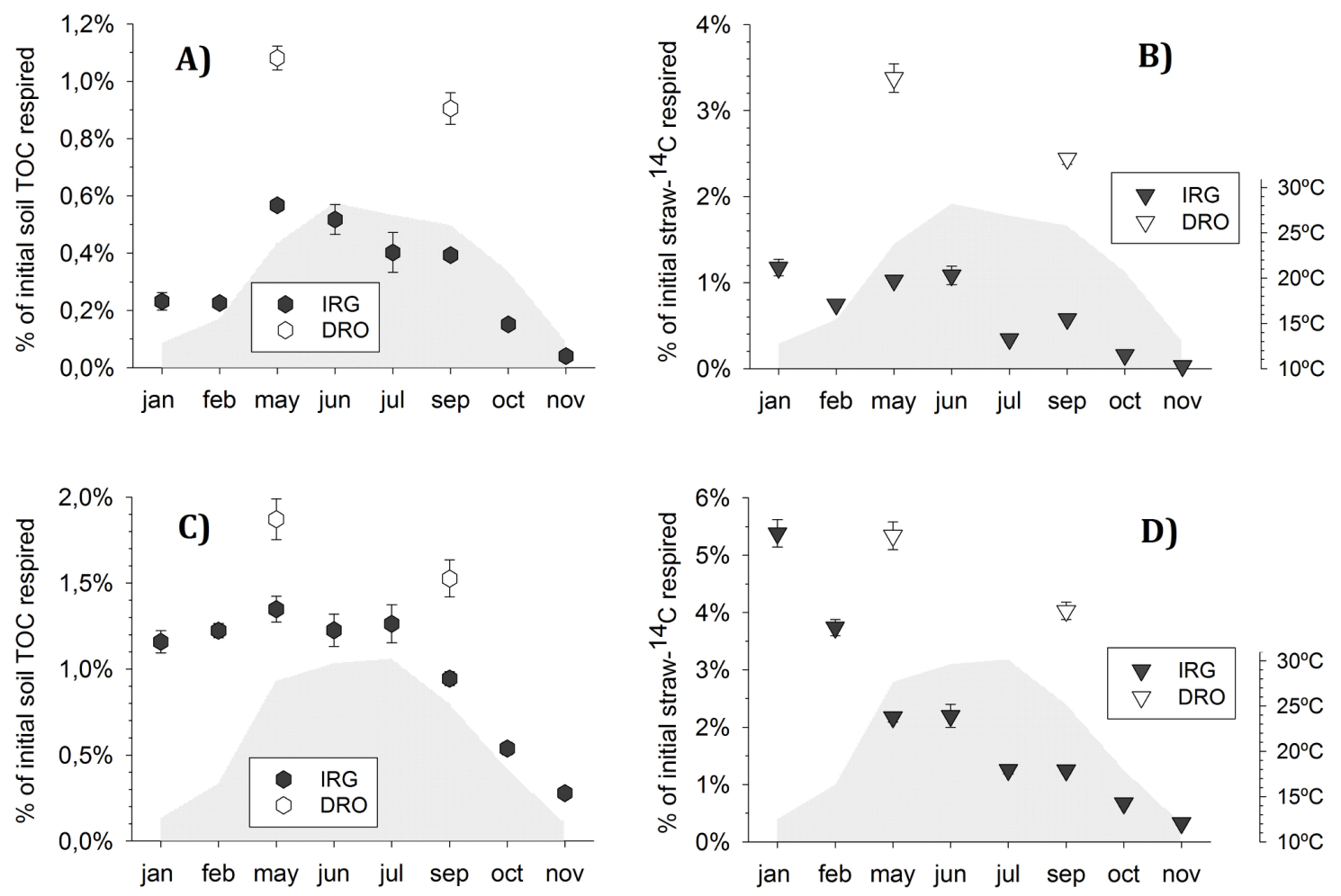
FIGURE 4 Linear regression between volumetric soil water content prior to rewetting (SWC; in water:soil volume \%) and the magnitude of Birch effect (3-day cumulative) as a proportion of the total (31-day cumulative) soil $\mathrm{CO}_{2}$-C losses upon rewetting. $\mathrm{N}=20$ (each form is mean $\pm \mathrm{SE}$; $\mathrm{n}=$ 2). White forms correspond to DRO treatment.

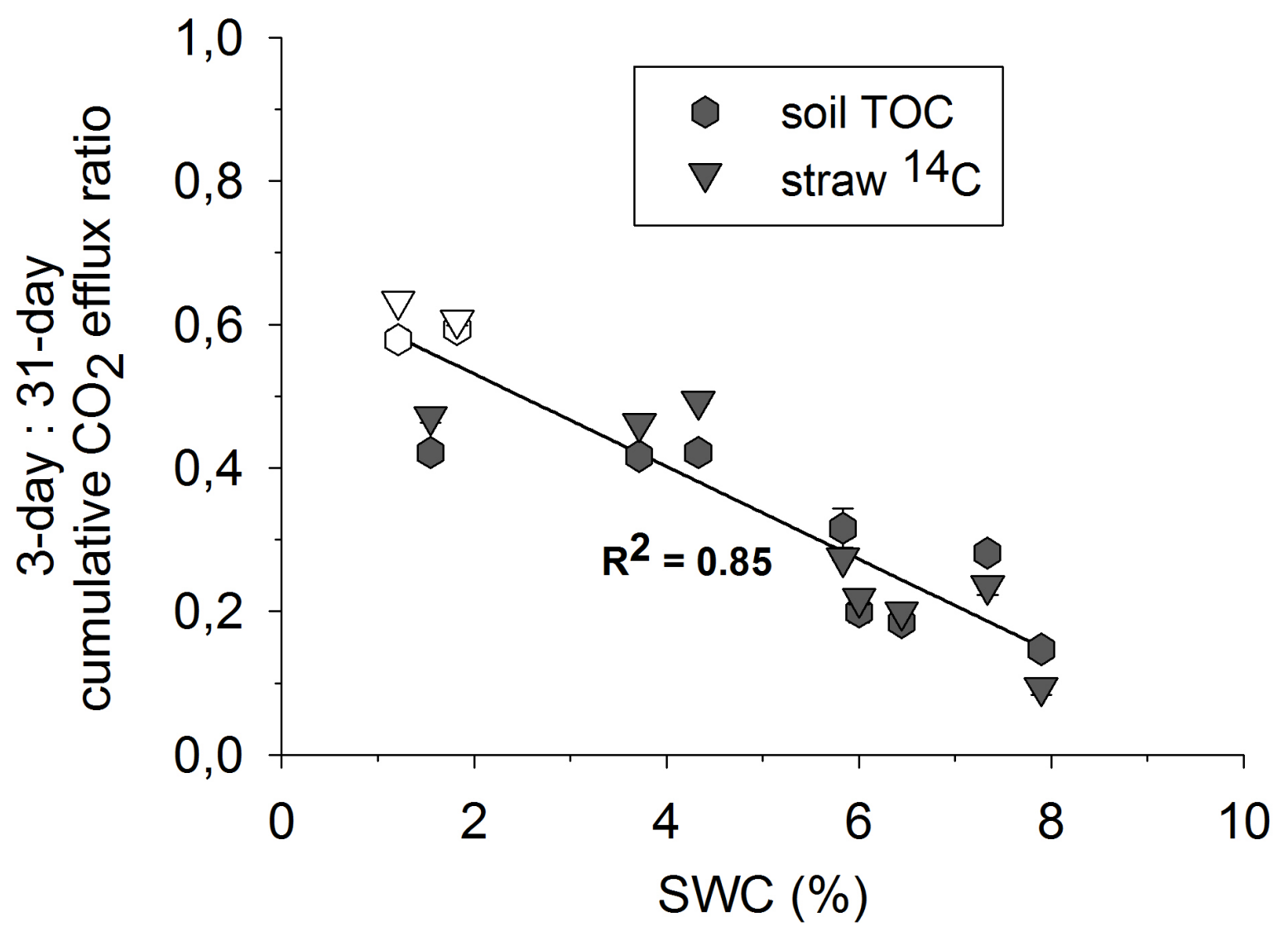


FIGURE 5 Evolution of the $\mathrm{CHCl}_{3}$-fumigated $\mathrm{K}_{2} \mathrm{SO}_{4}$-extractable organic $\mathrm{C}$ fraction (FEC) in the agricultural topsoil horizons at two different depths during the four soil destructive samplings prior to rewetting (mean \pm SE; $\mathrm{n}=3$ except Jan/07: $\mathrm{n}=4$ ). Right $\mathbf{A}$ ) total soil organic C (TOC), left hand-side figures; B) straw-derived ${ }^{14} \mathrm{C}$, right hand-side figures. Dotted areas show the microbial biomass $\mathrm{C}(\mathrm{MBC})$, resulting from the difference between fumigated (FEC) and non-fumigated extractable organic C (Vance et al. 1987; MBC values not corrected for extraction efficiency). Right $\mathrm{Y}$-axis units refer to the percentage of $\mathrm{C}$ respect that initially present in the soil horizon before incubation started, and is directly proportional to the left Y-axis.

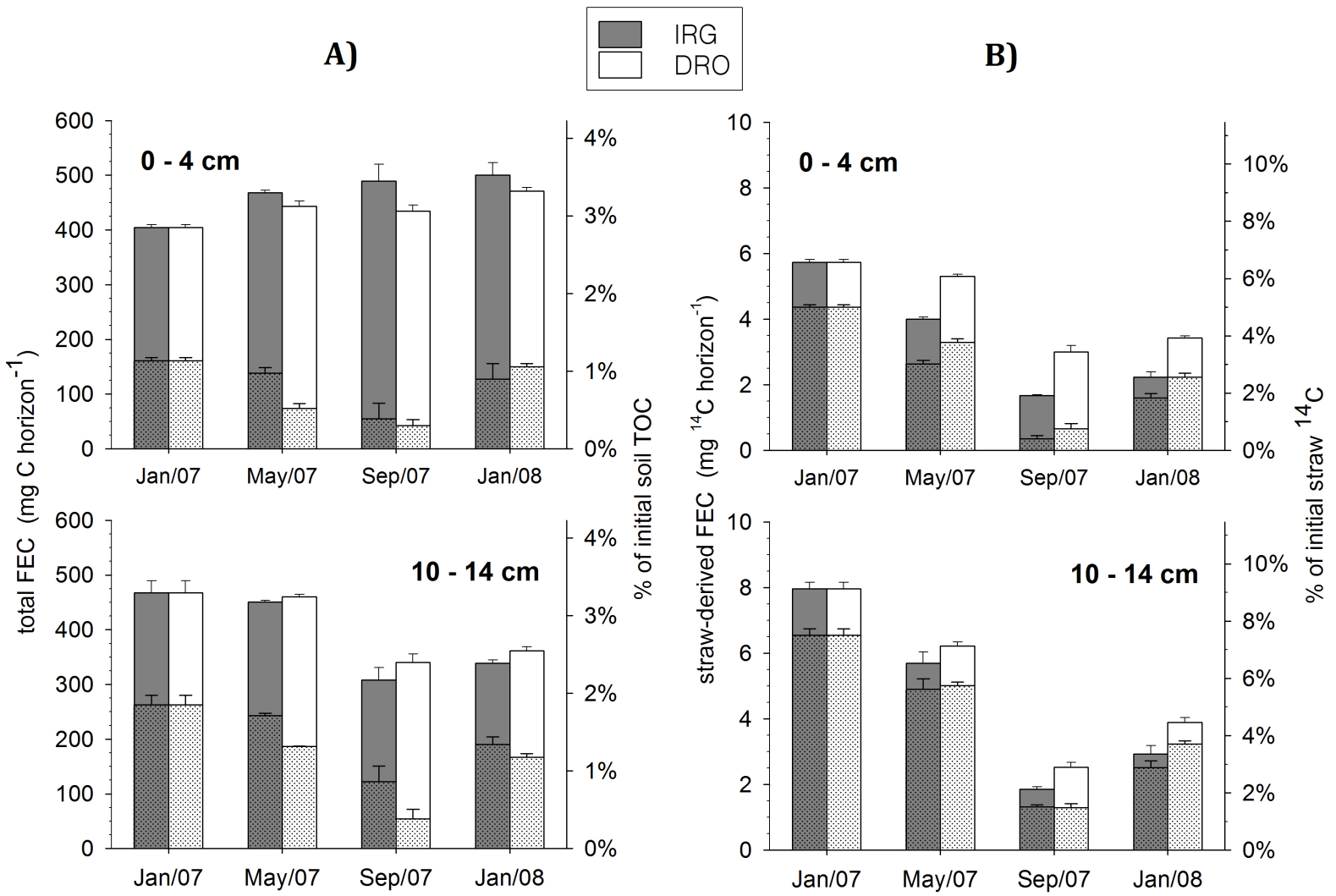


FIGURE 6 Relationship between gravimetric soil water content and microbial biomass C (MBC), previously standardized with respective to the amount of $\mathrm{CHCl}_{3}$-fumigated extractable organic $\mathrm{C}$ (FEC). Data from surface and subsurface horizons are included. A) total organic C; B) strawderived organic ${ }^{14} \mathrm{C}$. Black (IRG) and white dots (DRO) refer to the rewetting treatments; grey dots refer to Jan/07 sampling (prior to establishing the differential rewetting frequencies). First-order inverse polynomial equations were those that fitted best to empirical data.

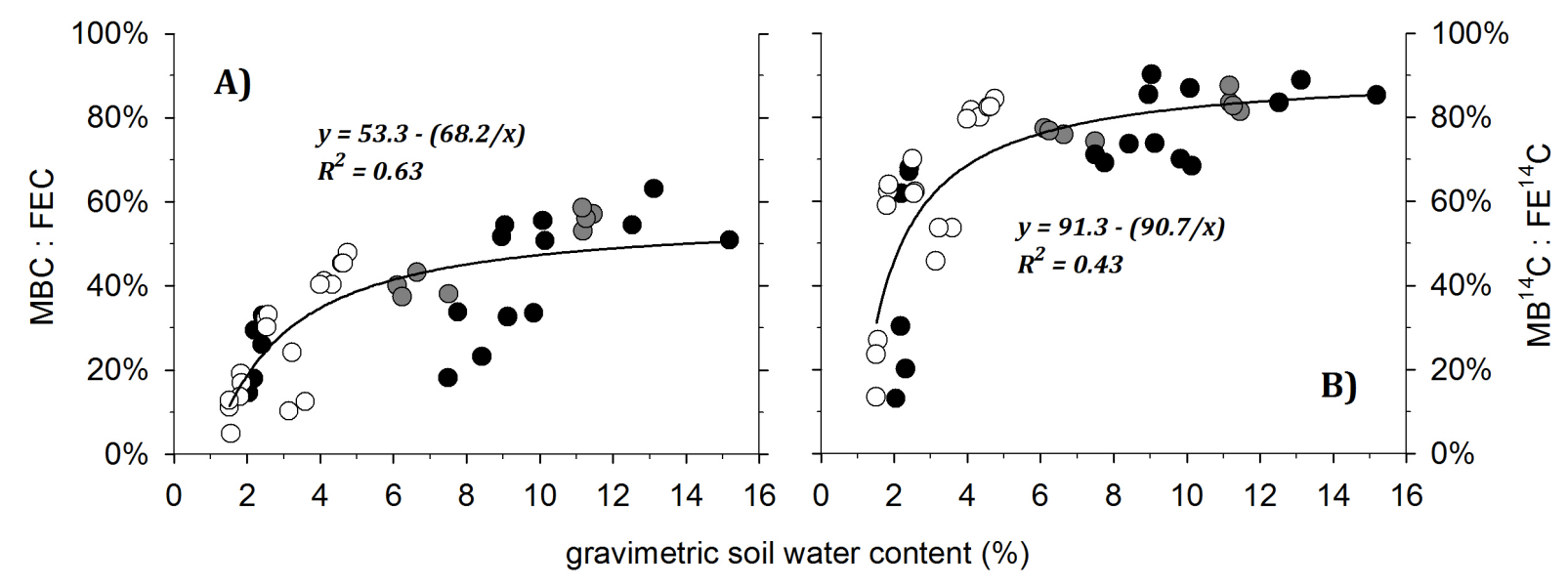

